\title{
Detection of two QTL on chicken chromosome 14 for keyhole lymphet heamocyanin
}

\author{
Maria Siwek • Joanna Szyda • Anna Slawińska • \\ Marek Bednarczyk
}

Received: 11 July 2011 /Revised: 10 October 2011 /Accepted: 10 October 2011 /Published online: 3 November 2011

(C) The Author(s) 2011. This article is published with open access at Springerlink.com

\begin{abstract}
A keyhole lymphet heamocyanin is an antigen which triggers Th1 type of immune response. A QTL for a primary immune response towards keyhole lymphet heamocyanin has been detected on chicken chromosome 14 in three populations. The results from the most recent population were inconsistent and varied depending on the applied QTL detection model. The major goal of the current study was the reanalysis of this data using a 2 QTL model. Additionally, in order to provide more accurate estimates of QTL effects and positions, epistasis between the QTL was considered as a potential important contributor to quantitative traits. Four statistical models were assumed: M1: A model assuming marginal additive effects of two QTL; M2: A model assuming marginal and epistatic additive effects of two QTL; M3: A model assuming marginal additive and dominance effects of two QTL; M4: A model assuming marginal additive and dominance effects of two QTL and all possible pairwise epistases. Two QTL with significant additive and dominance effects were detected on chicken chromosome 14 using model M3. One QTL was detected at $63 \mathrm{cM}$ between MCW0123 and ROS0005, another at $76 \mathrm{cM}$ between ROS0005 and MCW0225/NTN2Lsts1
\end{abstract}

M. Siwek $(\bowtie) \cdot$ A. Sławińska $\cdot$ M. Bednarczyk

Department of Animal Biotechnology, University of Technology and Life Sciences,

Mazowiecka 28,

85-225 Bydgoszcz, Poland

e-mail: siwek@utp.edu.pl

J. Szyda

Department of Animal Genetics, Wrocław University

of Environmental and Life Sciences,

Kożuchowska 7,

51-631 Wroclaw, Poland
(FDR $=0.0051)$. Modelling only additive effects resulted in a significantly worse fit. On the other hand, including epistatic effects did not improve fit significantly. The current study confirms previous reports of the QTL location on GGA14. A notable finding of this study is recognition of two closely related QTL for a keyhole lymphet heamocyanin response at the distal part of chicken chromosome 14 .

Keywords Chicken · Epistatic effect Immune trait . Multiple quantitative trait loci

\section{Introduction}

The identification of quantitative trait loci (QTL) usually follows the same pathway, which includes QTL detection in the whole genome scan, fine mapping and narrowing down the QTL region, confirmation of QTL location in the independent population and finally functional and positional candidate gene approach. In chicken, there is a long list of traits for which QTL have been detected (Abasht et al. 2006). Among them 83 are related to immune traits. So far, only a few of these QTL were confirmed in an independent population or fine mapped (Kim et al. 2006; Calenge et al. 2009). The current study is a follow up analysis of the QTL validated on a GGA14 for an immune response towards a non pathogenic antigen (Siwek et al. 2010).

In the current study we use a novel protein named keyhole lymphet heamocyanin (KLH). KLH is a coppercontaining high-molecular-weight protein. This protein is involved in the Th2 immune pathways in mammals (Bliss et al. 1996). This antigen has been used in several studies of chicken immunity (Minozzi et al. 2008; Minozzi et al. 2007; Hangalapura et al. 2004) and in QTL studies based 
on microsatellite markers (Siwek et al. 2003). This non pathogenic antigen is a potent immunostimulator used as hapten carrier to assess the magnitude of immune responses (Marcia et al. 2006). A QTL for a primary antibody response towards KLH has been first detected on GGA14 in two independent experimental populations (Siwek et al. 2003). The first confirmation of that QTL was performed on a feather pecking cross (Rodenburg and Koene 2001; Buitenhuis et al. 2003; Siwek et al. 2003). In the current experimental population, which is a White Leghorn and Green legged partidgelike cross (WL/ZK), a QTL on GGA14 was detected, but its most probable location varied depending on the applied QTL detection model (LDLA or Half sib; Siwek et al. 2010).

Because of the inconsistency of the WL/ZK results we were interested in checking whether a single or multiple QTL reside on GGA14. Consequently the major goal of the current study was the reanalysis of the data using a 2 QTL model. Additionally, in order to provide more accurate estimates of QTL effects (Zeng et al. 2005) and positions, epistasis between the QTL was considered as a potentially important contributor to quantitative traits (Mackay 2001).

\section{Materials and methods}

\section{Experimental population}

The experimental population was created from a cross between two breeds of chickens: White Leghorn (WL), which is a commercial layer and Green legged partidgelike (ZK), which is a Polish native chicken breed. Animals were kept on the farm at the University of Life Sciences in Lublin. We used floor system to keep the birds. Entire experimental population was vaccinated against Salmonella, Gumboro disease, bronchitis, Bourse Fabricius disease and encephalomyelitis. The reproduction of the population was as follows: five $\mathrm{F}_{0}$ roosters (WL) were mated to six - eight hens (ZK). From that cross of the parental breeds we obtained a $\mathrm{F}_{1}$ generation consisting of 115 individuals. Subsequently six $F_{1}$ roosters were mated to six - nine hens each. In the $F_{2}$ generation we obtained 506 individuals from 35 full sib families. Every time fertilized eggs were collected and incubated in an automatic incubator. The selection of the $\mathrm{F}_{1}$ parents was based on the KLH antibody titre in such a way that a high responding rooster was mated to low responding hens or the other way around.

\section{Genotypic data}

Genomic DNA was isolated from blood using a commercial kit MasterPure DNA Purification Kit for Blood (Epicenter ${ }^{\circledR}$ biotechnologies, MG 711100). PCR reaction was used to amplify microsatellite markers. Seven microsatellite markers located along $77 \mathrm{cM}$ of GGA14 were used for genotyping: MCW0296 (at 0 cM), ADL0200 (at $16 \mathrm{cM}$ ), ADL0118 (at $20 \mathrm{cM}$ ), MCW0136 (at $20 \mathrm{cM}$ ), MCW0123 (at $45 \mathrm{cM}$ ), ROS0005 (at $71 \mathrm{cM}$ ), and MCW0225/NTN2Lsts1 (at $77 \mathrm{cM}$ ). The reaction was carried out in a volume of 10 microlitres. Each reaction consisted of a mixture containing $75 \mathrm{mM}$ Tris- $\mathrm{HCl}(\mathrm{pH}$ 8.8), $20 \mathrm{mM}\left(\mathrm{NH}_{4}\right)_{2} \mathrm{SO}_{4}, 0.01 \%$ Tween $20,5.0 \mathrm{nmol}$ TMACl, $2.0 \mathrm{mM} \mathrm{MgCl}_{2}, 20 \mathrm{ng}$ DNA matrix, 0.25 units of recombinant Taq polymerase (Fermentas, Vilnius, Lithuania), and a pair of specific oligonucleotides for each marker, in an amount from 0.2 to 0.75 pmol each. After PCR reaction samples were loaded on a $6 \%$ denaturating polyacrylamide gel and subjected to electrophoresis. Fragment length analysis was based on a laser fluorescence detection, using an automatic plate sequenator Li-Cor 4200 , together with software designed for genotyping of microsatellite markers Saga GT.

\section{Phenotypic data}

Total antibody responses to KLH were measured in individual plasma samples obtained at 7 days after s.c. immunization with $1 \mathrm{mg} \mathrm{KLH}$ in $1 \mathrm{ml}$ PBS (pH 7.2) at 12 wk of age. Antibody titres to KLH of all birds were measured by an indirect ELISA as described by Sijben et al. (2000). Titres were expressed as the $\log _{2}$ values of the highest dilution giving a positive reaction.

\section{Statistical analysis}

Four mixed linear models with 2 QTL effects were applied to the data. All the models were evaluated for putative QTL positions every $1 \mathrm{cM}$ in a 2-dimentional grid.

M1: A model assuming marginal additive effects of two QTL:

$\mathbf{y}=\mathbf{Z} \alpha+\mathbf{X}_{a_{1}} \mathbf{q}_{a_{1}}+\mathbf{X}_{a_{2}} \mathbf{q}_{a_{2}}+\mathbf{e}$

where $\mathbf{y}$ contains trait values of $\mathrm{F}_{2}$ individuals, $\alpha \sim$ $N\left(0, \mathbf{A} \sigma_{\alpha}^{2}\right)$ is a vector of random polygenic effects of $\mathrm{F}_{2}$ animals with $\mathbf{A}$ representing an additive polygenic relationship matrix among individuals, and $\sigma_{\alpha}^{2}$ being a component of the total additive genetic variance attributed to polygenes, $\mathbf{q}_{a_{i}}$ represents a fixed additive effect of ith QTL, and $\mathbf{e} \sim N\left(0, \mathbf{I} \sigma_{e}^{2}\right)$ is a residual term, $\mathbf{X}_{a_{i}}$ is the matrix with coefficients for an additive effect of ith QTL calculated based on individuals' marker genotypes for a putative position of ith QTL using the QTL Express software (Seaton et al. 2002), $\mathbf{Z}$ is a design matrix for $\boldsymbol{\alpha}$, which is independent of the putative QTL positions considered. 
M2: A model assuming marginal and epistatic additive effects of two QTL:

$\mathbf{y}=\mathbf{Z} \alpha+\mathbf{X}_{a_{1}} \mathbf{q}_{a_{1}}+\mathbf{X}_{a_{2}} \mathbf{q}_{a_{2}}+\mathbf{X}_{a_{1} a_{2}} \mathbf{q}_{a_{1} a_{2}}+\mathbf{e}$,

where $\mathbf{q}_{a_{1} a_{2}}$ represents an additive-by-additive epistatic effect between both QTL with the corresponding coefficient matrix $\mathbf{X}_{a_{1} a_{2}}$.

M3: A model assuming marginal additive and dominance effects of two QTL:

$\mathbf{y}=\mathbf{Z} \alpha+\mathbf{X}_{a_{1}} \mathbf{q}_{a_{1}}+\mathbf{X}_{a_{2}} \mathbf{q}_{a_{2}}+\mathbf{X}_{d_{1}} \mathbf{q}_{d_{1}}+\mathbf{X}_{d_{2}} \mathbf{q}_{d_{2}}+\mathbf{e}$

where $\mathbf{q}_{d_{i}}$ represents a vector of fixed dominance effect of ith QTL with the corresponding coefficient matrix $\mathbf{X}_{d_{i}}$.

M4: A model assuming marginal additive and dominance effects of two QTL and all possible pairwise epistases:

$$
\begin{aligned}
\mathbf{y}= & \mathbf{Z} \alpha+\mathbf{X}_{a_{1}} \mathbf{q}_{a_{1}}+\mathbf{X}_{a_{2}} \mathbf{q}_{a_{2}}+\mathbf{X}_{d_{1}} \mathbf{q}_{d_{1}}+\mathbf{X}_{d_{2}} \mathbf{q}_{d_{2}}+\mathbf{X}_{a_{1} a_{2}} \mathbf{q}_{a_{1} a_{2}} \\
& +\mathbf{X}_{a_{1} d_{2}} \mathbf{q}_{a_{1} d_{2}}+\mathbf{X}_{d_{1} a_{2} \mathbf{q}_{2}} \mathbf{q}_{d_{1} a_{2}}+\mathbf{X}_{d_{1} d_{2} q_{2}} \mathbf{q}_{d_{1} d_{2}}+\mathbf{e}
\end{aligned}
$$

where $\mathbf{q}_{a_{1} d_{2}}, \mathbf{q}_{d_{1} a_{2}}$, and $\mathbf{q}_{d_{1} d_{2}}$ represent respectively an additive-by-dominance, dominance-by-additive, and dominance-by-dominance epistatic effects between both QTL with the corresponding coefficient matrices $\mathbf{X}_{a_{1} d_{2}}$, $\mathbf{X}_{d_{1} a_{2}}$, and $\mathbf{X}_{d_{1} d_{2}}$. Note that all the coefficient matrices for epistatic effects result from the multiplication of the corresponding coefficient matrices for marginal QTL effects.

Model parameters were estimated using Maximum Likelihood, under the assumption that the variance component underlying a random polygenic effect are known (i.e. this variance component was not estimated). Models were compared using the likelihood ratio test $\lambda=-2\left[\ln L\left(\hat{\beta}_{0}\right)-\ln L\left(\hat{\beta}_{1}\right)\right]$, where $L\left(\hat{\beta}_{0}\right)$ and $L\left(\hat{\beta}_{1}\right)$ represent values of the likelihood function for a more parsimonious and a less parsimonious model respectively. The nominal $\mathrm{P}$ values of the test were calculated based on the $\chi^{2}$ distribution with the number of degrees of freedom corresponding to a difference in the number of parameters between the two models. Since 4466 pairwise location for the two QTL were tested, the false discovery rate (FDR; Benjamini and Hochberg 1995) was calculated, based on the nominal $\mathrm{P}$ values, in order to circumvent the multiple testing problem. The FDR adjusted nominal $\mathrm{P}$ values $\left(\mathrm{P}^{\mathrm{FDR}}\right)$ were calculated as follows: $P_{4466}^{F D R}=P_{4466}, \forall i \in\{2, \cdots, 4465\}: P_{4466-i}^{F D R}=\min \left(P_{4466-i+1}^{F D R}\right.$, $\left.\frac{4466}{4466-i} P_{4466-i}\right), P_{1}^{F D R}=\min \left(P_{2}^{F D R}, 4466 P_{1}\right)$, where index $i$ represents the order of nominal $\mathrm{P}$ values from the smallest $(i=1)$ to the largest $(i=4466)$. Estimation of model parameters and $\mathrm{P}$ value adjustment were calculated using the SAS software (SAS Institute Inc.). PROC MIXED procedure was used for the estimation of model parameters and PROC MULTTEST procedure was used for $\mathrm{P}$ value adjustment.

\section{Results and discussion}

Two QTL with significant additive and dominance effects at $63 \mathrm{cM}$ between MCW0123 and ROS0005 and $76 \mathrm{cM}$ between

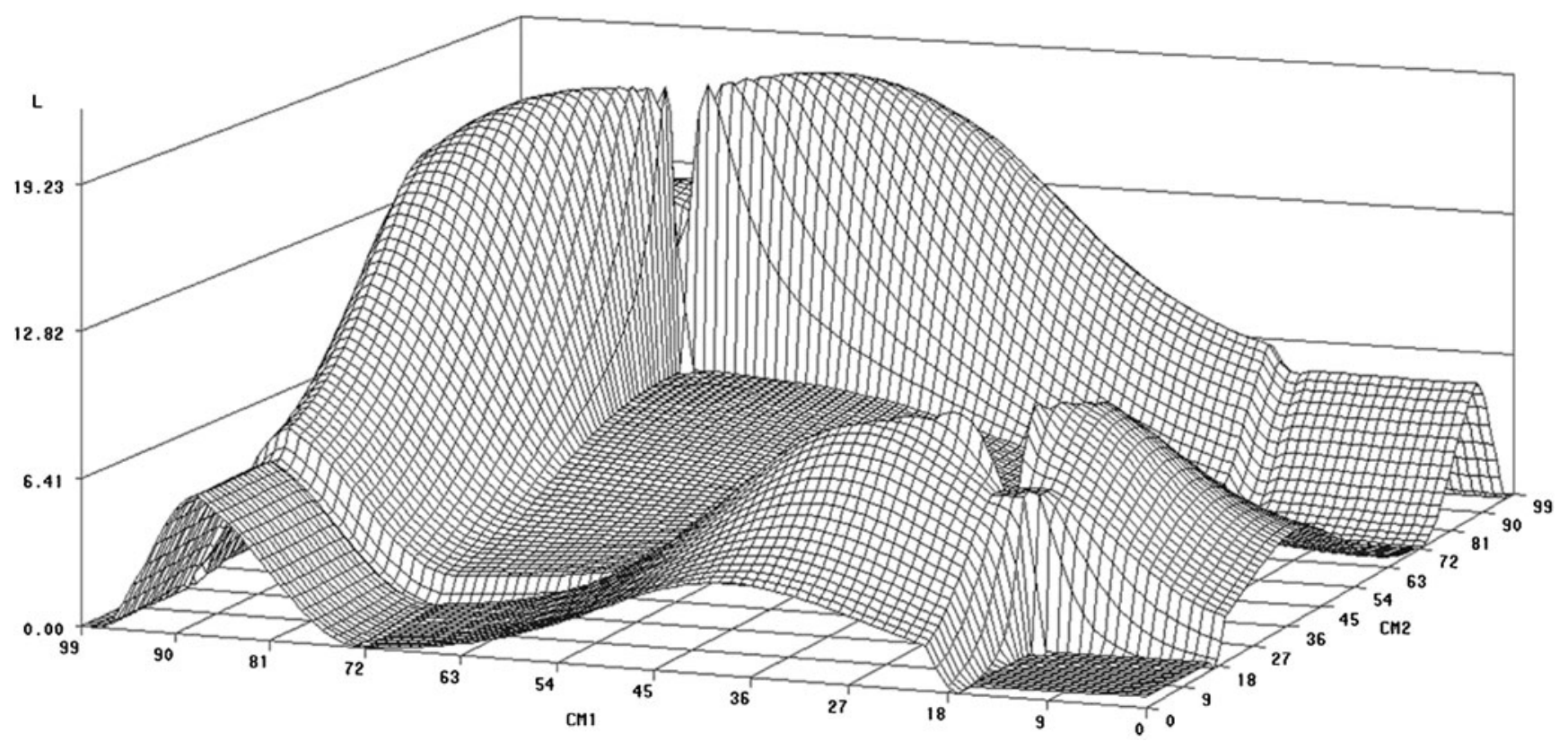

Fig. 1 Likelihood ratio test profile for a two QTL model. Test corresponds to the hypothesis of additive vs. additive and dominance effects (M1 vs. M3) of the QTL for a primary immune response towards keyhole lymphet heamocyanin. CM1 and CM2 - distance in centiMorgan; L - likelihood ratio test 
ROS0005 and MCW0225/NTN2Lsts1 (FDR=0.0051; Fig. 1) were detected on chicken chromosome 14 (GGA14). Modelling only additive effects resulted in a significantly worse fit. On the other hand, including epistatic effect did not improve fit significantly.

Non-random LD in chickens, which extends over short distances reported by Andreescu et al. 2007, justifies the choice of linkage mapping over the association analysis as it was done in the presented manuscript.

According to the Animal QTL data base chicken chromosome 14 harbours altogether 28 QTL for various traits (http://www.animalgenome.org/cgi-bin/QTLdb/GG/ index). We were particularly interested in a QTL for a primary antibody response towards KLH. This trait has been studied in three experimental populations: SRBC population - which is a cross between two chicken lines divergently selected for high $(\mathrm{H})$ and low (L) primary antibody response towards sheep red blood cells (SRBC) (Siwek et al. 2003); F/P population - a cross between two chicken lines which differed in their propensity for feather pecking (Rodenburg and Koene 2001) and the White Leghorn/ ZK cross (Siwek et al. 2010). In all three populations (SRBC, F/P, WL/ZK) all methods used for the analysis were the same, individuals received the same treatment which allows comparison of the results from three experiments. The only difference was the time of the KLH injection. The $\mathrm{F} / \mathrm{P}$ population birds were injected at 36 weeks of age, and at 12 weeks of age in the SRBC and WL/ZK populations. At first a QTL for a primary antibody response towards KLH was detected in the SRBC population in the whole genome scan approach. The evidence of the QTL for a KLH antigen was provided by two models: paternal half - sib model, and a line cross model. Both models pointed towards the same location between microsatellite markers: MCW0123 and MCW0225 (Siwek et al. 2003). First confirmation of this QTL was performed in the F/P population. Paternal half - sib model, which was applied to analyse the dataset, pointed a QTL location towards the proximal part of GGA14 in the marker bracket: MCW0296 - ADL0118. Despite that the time of the KLH stimulation differed in both populations, the confidence interval estimated for a QTL position on GGA14 was large, the marker density in both cases (SRBC population and $\mathrm{F} / \mathrm{P}$ population) was low which drove us to the conclusion that we dealt with the same QTL in both populations and slightly different peak position is due to the diverse time of KLH injection or differences in the distribution of recombination events along GGA14. The second confirmation of the QTL for a primary antibody response towards KLH on GGA14 was performed in the experimental cross of White Leghorn and Green legged partidgelike (Siwek et al. 2010). In the WL/ZK reference population a QTL for a primary antibody response towards
KLH was detected in the marker bracket: MCW0136 MCW0125 with a maternal half - sib analysis model. In fact there were two QTLs detected on GGA14 with initial half sib linkage analysis models. One QTL in the middle part of GGA14 detected with maternal half sib QTL model, presented in Fig. 1A (Siwek et al. 2010) and a second one at the distal part of GGA14 detected with paternal half sib QTL model. The second QTL was just below the significance threshold (Table 3, Siwek et al. 2010). Another model (LDLA) applied to this data set moved the QTL peak towards the end of the chromosome, to the marker bracket: ROS0005 - MCW0225. Multiple QTL analysis confirmed location of the QTL pointed by LDLA analysis and separated QTL location detected with the maternal - half sib model as a second independent QTL.

Results of the candidate genes approach have been reported elsewhere (Siwek et al. 2010). In short, three candidate genes where selected in the QTL region: AXIN1 (axis inhibition protein 1), TRAP (TNF receptor-associated protein 1), and MAPK8IP3 (mitogen-activated protein kinase 8 interacting protein 3). Given the current findings on two QTL located at the distal part of GGA14 these three genes are distributed over the two QTL marker brackets. AXIN1 and TRAP being located in the first QTL region and MAPK8IP3 being located in the second QTL region. These genes have been genotyped with SNP located in gene exons. Statistical analyses of single SNP associations were performed pointing out two SNPs within the AXIN1 gene as significantly associated with the primary antibody response to KLH (Siwek et al. 2010). Even though the presented candidate gene approach does not provide solid evidence for a second gene related with a trait of interest in the other QTL region, there is a long list of hypothetical proteins and undefined sequences in the distal part of chicken chromosome 14 which gives room for new detections.

In summary, we hereby present results of a multi QTL analysis aimed at the identification of QTL involved in the primary antibody response to KLH. Current study confirms previous reports of the QTL location on GGA14. A notable finding of this study is recognition of two closely related QTL for KLH response at the distal part of chicken chromosome 14.

Acknowledgement The study was financed by the Polish State Committee for Scientific Research, grants no. N N311 450434 and N N311 558640.

Open Access This article is distributed under the terms of the Creative Commons Attribution Noncommercial License which permits any noncommercial use, distribution, and reproduction in any medium, provided the original author(s) and source are credited. 


\section{References}

Andreescu C, Avendano S, Brown SR, Hassen A, Lamont SJ, Dekkers JCM (2007) Linkage disequilibrium in related breeding lines of chickens. Genetics 177:2161-2169

Abasht B, Dekkers JC, Lamont SJ (2006) Review of quantitative trait loci identified in the chicken. Poult Sci 85:2079-2096. Erratum: Poult. Sci. 86:206

Benjamini Y, Hochberg Y (1995) Controlling the false discovery rate: a Practical and Powerful Approach to Multiple Testing. Journal of the Royal Statistical Society B 57:289-300

Bliss J, Van Cleave V, Murray K, Wiencis A, Ketchum M, Maylor R, Haire T, Resmini C, Abbas AK, Wolf SF (1996) IL-12, as an adjuvant, promotes a $\mathrm{T}$ helper 1 cell, but does not suppress a $\mathrm{T}$ helper 2 cell recall response. J Immunol 156:887-864

Buitenhuis AJ, Rodenburg TB, van Hierden Y, Siwek M, Cornelissen SJB, Nieuwland MGB, Crooijmans RPMA, Groenen MAM, Koene P, Korte SM, Bovenhuis H, van der Poel JJ (2003) Mapping Quantitative Trait Loci affecting feather pecking behaviour and stress response in laying hens. Poult Sci $82: 1215-1222$

Calenge F, Lecerf F, Demars J, Feve K, Vignoles F, Pitel F, Vignal A, Velge P, Sellier N, Beaumont C (2009) QTL for resistance to Salmonella carrier state confirmed in both experimental and commercial chicken lines. Anim Genet 40:590-597

Hangalapura BN, Nieuwland MG, de Vries RG, van den Brand GH, Kemp B, Parmentier HK (2004) Durations of cold stress modulates overall immunity of chicken lines divergently selected for antibody responses. Poult Sci 83:765-775

Kim ES, Hong YM, Min W, Lillehoj HS (2006) Fine-mapping of coccidia-resistant quantitative trait loci in chickens. Poult Sci 85:2028-2030

Marcia L, Delacre M, Abboud G (2006) Impairment of dendritic cell functionality and steady-state number in obese mice. J Immunol 177:5997-6006
Minozzi G, Parmentier HK, Nieuwland MG, Bed'hom B, Minvielle F, Gourichon D, Pinard-van der Laan MH (2007) Antibody responses to keyhole limpet hemocyanin, lipopolysaccharide, and Newcastle Disease virus vaccine in F2 and backcrosses of white Leghorn lines selected for two different immune response traits. Poult Sci 86:1316-1322

Minozzi G, Parmentier HK, Mignon-Grasteau S, Nieuwland MGB, Bed'hom B, Gourichon D, Minvielle F, Pinard-van der Laan MH (2008) Correlated effects of selection for immunity in White Leghorn chicken lines on natural antibodies and specific antibody responses to KLH and M. butyricum. BMC Genetics 9, 5

Rodenburg B, Koene P (2001) Comparison of individual and social feather pecking tests in two lines of White Leghorn Laying hens. In: Proceedings of the Six European Symposium on Poultry Welfare, Zollikofen, Switzerland, pp 250-253

Seaton G, Haley CS, Knott SA, Kearsey M, Visscher PM (2002) QTL Express: mapping quantitative trait loci in simple and complex pedigrees. Bioinformatics 18:339-340

Sijben JW, de Groot H, Nieuwland MGB, Schrama JW, Parmentier HK (2000) Dietary linoleic acid divergently affects immune responsiveness of growing layer hens. Poult Sci 79:1106-1115

Siwek M, Buitenhuis AJ, Cornelissen SJB, Nieuwland MGB, Bovenhuis H, Crooijmans RPMA, Groenen MAM, De VriesReilingh G, Parmentier HK, Van der Poel JJ (2003) Detection of different QTL for antibody response to keyhole lymphet haemocynain and mycobacterium butiricum in two unrelated populations of laying hens. Poult Sci 82:1845-1842

Siwek M, Slawinska A, Nieuwland M, Witkowski A, Zięba G, Minozzi G, Knol EF, Bednarczyk M (2010) A quantitative trait locus for a primary antibody response to keyhole limpet hemocyanin on chicken chromosome 14-Confirmation and candidate gene approach. Poult Sci 89:1850-1857

SAS Institute Inc., SAS 9.1.3 Help and Documentation, Cary, NC: SAS Institute Inc., 2000-2004

Zeng ZB, Wang T, Zou W (2005) Modeling quantitative trait loci and interpretation of models. Genetics 169:1711-1725 